\title{
Neuroendocrine regulation of salt and water metabolism
}

S.M. McCann ${ }^{1}$,

C.R. Franci ${ }^{2}$,

A.L.V. Favaretto ${ }^{2}$,

J. Gutkowska ${ }^{3}$ and J. Antunes-Rodrigues ${ }^{2}$
1Pennington Biomedical Research Center (LSU), Baton Rouge, LA 70808-4124, USA

${ }^{2}$ Departamento de Fisiologia, Faculdade de Medicina de Ribeirão Preto,

Universidade de São Paulo, 14049-900 Ribeirão Preto, SP, Brasil

${ }^{3}$ Centre de Recherche Hôtel-Dieu de Montreal,

Pavilion Marie-de-la-Ferre, Montréal, Quèbec H2W 1T8, Canada

\author{
Correspondence \\ S.M. McCann \\ Pennington Biomedical Research \\ Center (LSU) \\ 6400 Perkins Road \\ Baton Rouge, LA 70808-4124 \\ USA \\ Fax: 504-763-3030 \\ Presented at the International \\ Symposium "Neuroendocrine \\ Control of Body Fluid Homeostasis", \\ Ribeirão Preto, SP, Brasil, \\ August 17-20, 1996. \\ Research supported by the \\ National Institutes of Health \\ (Nos. DK43900 and MH51853) to \\ S.M. McCann, the MRC of Canada \\ (Nos. MT10337 and MT11674) to \\ J. Gutkowska, FAPESP \\ (Nos. 91/0567-0, 94/3805-7 and \\ 96/023-3) and $\mathrm{CNPq}$ \\ (Nos. 52/593/94-8 and 52/764/96-0) \\ to J. Antunes-Rodrigues.
}

Received November 29, 1996

Accepted January 15, 1997

\begin{abstract}
Neurons which release atrial natriuretic peptide (ANPergic neurons) have their cell bodies in the paraventricular nucleus and in a region extending rostrally and ventrally to the anteroventral third ventricular $(\mathrm{AV} 3 \mathrm{~V})$ region with axons which project to the median eminence and neural lobe of the pituitary gland. These neurons act to inhibit water and salt intake by blocking the action of angiotensin II. They also act, after their release into hypophyseal portal vessels, to inhibit stressinduced ACTH release, to augment prolactin release, and to inhibit the release of LHRH and growth hormone-releasing hormone. Stimulation of neurons in the $\mathrm{AV} 3 \mathrm{~V}$ region causes natriuresis and an increase in circulating ANP, whereas lesions in the AV $3 \mathrm{~V}$ region and caudally in the median eminence or neural lobe decrease resting ANP release and the response to blood volume expansion. The ANP neurons play a crucial role in blood volume expansion-induced release of ANP and natriuresis since this response can be blocked by intraventricular (3V) injection of antisera directed against the peptide. Blood volume expansion activates baroreceptor input via the carotid, aortic and renal baroreceptors, which provides stimulation of noradrenergic neurons in the locus coeruleus and possibly also serotonergic neurons in the raphe nuclei. These project to the hypothalamus to activate cholinergic neurons which then stimulate the ANPergic neurons. The ANP neurons stimulate the oxytocinergic neurons in the paraventricular and supraoptic nuclei to release oxytocin from the neural lobe which circulates to the atria to stimulate the release of ANP. ANP causes a rapid reduction in effective circulating blood volume by releasing cyclic GMP which dilates peripheral vessels and also acts within the heart to slow its rate and atrial force of contraction. The released ANP circulates to the kidney where it acts through cyclic GMP to produce natriuresis and a return to normal blood volume.
\end{abstract}

Key words

- Anteroventral third ventricle (AV3V) region

- Blood volume expansion

- ANP neurons

- Oxytocin

- Vasopressin

- Plasma ANP

- Thirst

- Salt intake

- Natriuresis

- Kaliuresis 


\section{Introduction}

Clinical studies involving patients with diabetes insipidus and the description of cases with brain lesion, which had either hypo- or hypernatremia, suggested an important role for the hypothalamus in the control of water and salt intake and excretion (1). In the early fifties, Andersson and McCann (2) showed that microinjection of hypertonic saline into the hypothalamus of goats could induce drinking.

Electrical stimulation in the same region which evoked drinking following injection of hypertonic saline caused reproducible drinking with a very slight delay and with little aftereffect, such that the animals could drink a total 30 to $40 \%$ of their body weight in water. Stimulation also could evoke milk ejection via release of oxytocin (OT) and antidiuresis via release of antidiuretic hormone (vasopressin (VP)). Stimulation in or around the paraventricular nucleus, a site of origin of OT and VPergic neurons, produced natriuresis (3). It is interesting to note that the area that induced natriuresis is also the site of cell bodies of atrial natriuretic peptide (ANP) neurons (4).

In dogs, lesions in the medial hypothalamus surrounding the third ventricle $(3 \mathrm{~V})$, some of which extended into the anteroventral portion of the third ventricle (AV3V), produced complete adipsia but the animals tended to recover. During the adipsic period the animals would not drink water, but would drink fluid food in the form of milk or broth. During the adipsic period the animals were given water by gavage but still developed pronounced hypernatremia (5). A similar syndrome occurs following AV3V lesions in rats (6).

\section{Transmitters in the hypothalamic control of fluid and electrolyte homeostasis}

Much later, Andersson et al. (7) microinjected hypertonic saline into the $3 \mathrm{~V}$ of goats and found that not only did it evoke reproducible drinking in the animals in contrast to the difficulty of repeatability following injections into the tissue, but also evoked a marked natriuresis. This effect was then confirmed following $3 \mathrm{~V}$ injection of hypertonic saline into rats (8), and the role of various brain transmitters in the control of water, sodium chloride and food intake and sodium excretion was then studied. Intraventricular injection of carbachol induced a dramatic, rapid 15 -fold increase in water intake, whereas none of the other adrenergic or cholinergic drugs was effective (9), which was in agreement with earlier findings of Grossman (10) injecting drugs into hypothalamic tissue. Both carbachol and isoproterenol, a beta adrenergic agonist, evoked large increases in salt intake. Again, other drugs failed to produce significant effects (9).

Hypertonic saline injected into the $3 \mathrm{~V}$ produced a delayed increase in both water intake and food intake but did not alter salt intake (9). Therefore, it is clear that there is a cholinergic synapse in the pathways that mediate water intake $(9,10)$, whereas both cholinergic and adrenergic synapses are involved in mediation of salt intake (9). Little further research along these lines has been undertaken.

The role of various transmitters in the natriuretic response to the $3 \mathrm{~V}$ injection of hypertonic saline was studied, and intraventricular injection of carbachol evoked a dramatic natriuretic response which mimicked the response to intraventricular hypertonic saline (8). Both natriuretic and kaliuretic responses and an increase in the sodium/ potassium ratio were induced by intraventricular injection of norepinephrine or carbachol, whereas dopamine had no effect (11). The beta receptor stimulator, isoproterenol, induced an antinatriuretic and antikaliuretic effect. To determine the nature of the receptors involved, adrenergic blockers were injected. The alpha adrenergic blocker, phentolamine, abolished the natriuretic response 
to intraventricular hypertonic saline and to norepinephrine and carbachol. In contrast, the beta adrenergic blocker, propranolol, induced natriuresis and kaliuresis when injected alone and had an additive effect when its injection was followed by that of norepinephrine or hypertonic saline. Propranolol also potentiated the natriuretic response to carbachol. Cholinergic blockade with atropine diminished the response to norepinephrine and blocked the natriuretic response to hypertonic saline. It was suggested that sodium receptors in the ventricular wall (12) modify renal sodium excretion by a stimulatory pathway involving cholinergic and alpha adrenergic receptors and inhibit sodium excretion by a tonically active beta-receptor pathway (13). Much later, beta receptors were described in the hypothalamus (14).

Covian, Antunes-Rodrigues and their associates (15) mapped the various pathways in the CNS controlling salt excretion and obtained similar results concerning the role of cholinergic and adrenergic receptors. Cholinergic or adrenergic stimulation of the medial septal area, medial preoptic area, anterior lateral hypothalamus, and subfornical organ as well as the anterior portion of the AV3V induced dose-related natriuresis accompanied by a lesser kaliuresis. Thus, considerable evidence indicates that the medial preoptic area, anterior lateral hypothalamus, subfornical organ, AV3V, habenula, stria medullaris, supraoptic nucleus, and medial septal area are organized in a neural circuit involved in the regulation of water and sodium intake and excretion (15). Specific hypothalamic lesions in this circuit altered salt intake (16). The role played by the CNS in the control of renal sodium excretion was demonstrated by other investigators as well $(8,12)$.

\section{Natriuretic hormones}

During the sixties much attention was paid to the possibility of the existence of a natriuretic hormone. The idea stemmed from the experiments of de Wardener and Clarkson (17) showing that natriuresis could occur following body fluid expansion even though factors such as increased glomerular filtration rate or changes in aldosterone secretion were eliminated. Davis and Freeman (18) obtained evidence for a circulating natriuretic factor in volume-expanded dogs by crosscirculation experiments.

Cort et al. (19) reported the purification of a hypothalamic natriuretic factor and claimed it was an OT analog. Orias and McCann (20-22) confirmed that both VP and $\mathrm{OT}$ are natriuretic. Also alpha- and betamelanocyte-stimulating hormone $(\alpha-\mathrm{MSH}$, $\beta-\mathrm{MSH}$ ) have natriuretic activity in conscious water-loaded male rats. It is now known that $\alpha$-MSH is produced in neurons in the brain and is also released from the intermediate lobe of the pituitary, so it was possible that the natriuretic hormone is MSH; however, it is still not clear if MSH has a physiologic role in the induction of natriuresis.

Since there was considerable evidence suggesting that there was a natriuretic hormone in the hypothalamus and it could be related to OT, Morris et al. (23) evaluated the effect of median eminence lesions on the natriuretic responses to hypertonic saline and carbachol or norepinephrine injected into the $3 \mathrm{~V}$, since if indeed there were a hypothalamic natriuretic hormone, it might be expected to gain exit to the general circulation via the neurohypophysis. These animals had lesions which destroyed most of the median eminence and thereby induced diabetes insipidus, because of interruption of the supraopticohypophyseal tract and consequent elimination of VP and OT secretion. The median eminence lesions blocked the natriuresis, kaliuresis and antidiuresis which followed the injection of hypertonic saline or norepinephrine into the $3 \mathrm{~V}$. Sham lesion did not interfere with the responses. Hypophysectomy did not block the responses, which ruled out the participation of anterior pituitary hormones (23). Orias and McCann 
(24) showed that the responses still occurred in rats with hereditary diabetes insipidus which lacked VP. Thus, although natriuretic, both VP and MSH were eliminated as essential components of the natriuretic responses. Therefore, we suggested that these lesions had interrupted the secretion of a natriuretic hormone involved in the induction of central natriuresis.

\section{Atrial natriuretic peptide}

We were amazed to become aware of the discovery of atrial natriuretic factor (peptide) (ANP) in 1983 (25). It had been known that dilation of the atria could produce diuresis from the pioneering experiments of Gauer and Henry (26). At that time it was thought that distension of the atria activated impulses which traveled up the vagus to inhibit the release of antidiuretic hormone. The decreased release of this hormone was thought to be responsible for the diuresis. Immersion in baths had been known to evoke diuresis since the mid 19th century. Immersion probably increased venous return to the heart and dilated the atria.

Therefore, it was a great shock to find that this was not due to a reflex activation of the brain but instead was due to the release of ANP from the right atrium of the heart. Space does not permit the elaboration of the history of ANP; however, the thinking then changed to the idea that natriuresis following volume expansion was due to secretion of this peptide from the atria which circulated to the kidneys and evoked natriuresis (27).

\section{The brain ANPergic neurons}

The demonstration of ANP in extracts from various hypothalamic regions (28) and the evidence that ANP had opposite actions to those of angiotensin II (AII) in every site so far studied (29) led us to hypothesize that ANP might have opposite actions to those of
AII in the control of water intake and that it might be the long sought hypothalamic natriuretic hormone. Indeed, it is now known that ANPergic neurons are localized in the region extending from the paraventricular nucleus rostrally to the organum subfornicalis and ventrally to the organum vasculosum lamina terminalis, areas known to be implicated in thirst (30), and their axons also project caudally and ventrally to the median eminence and neural lobe (4). There they terminate in proximity to either the long or short portal vessels, so that the peptide could be transported to the anterior pituitary and also into the general circulation.

\section{The ANPergic neurons in water and salt intake}

Injection of ANP into the $3 \mathrm{~V}$ of waterdeprived rats induced a dose-related inhibition of drinking with doses of 1.0 or $2.0 \mathrm{nmol}$ of ANP injected into the ventricle. Inhibition could only be obtained following intravenous injections of the peptide at the higher 2.0-nmol dose, indicating a central action of the intraventricularly injected peptide (31). ANP also blocked AII-induced drinking. This inhibitory response was present at doses of intraventricularly injected AII ranging from 4.8 to $25.0 \mathrm{pmol}$; however, the $1.0-\mathrm{nmol}$ dose of ANP given 5 min before AII infusion was unable to block responses to much higher doses of AII ranging from 96.0 to 956.0 pmol (31).

Since AII also increases salt intake, we speculated that ANP would have the opposite effect and inhibit saline intake when injected into the $3 \mathrm{~V}$ of conscious salt-depleted rats. Animals were salt-depleted by 4 days of salt restriction followed by peritoneal dialysis with $5 \%$ glucose solution to produce hyponatremia. Intake of $1.5 \%$ sodium chloride solution was suppressed dramatically by a minimal effective dose of 0.2 nmol of ANP. There was no additional effect with a 10-fold higher dose. The suppression 
was maintained during the $24 \mathrm{~h}$ after central injection of the peptide; however, in this case the inhibition was somewhat greater with the higher dose of ANP. In contrast, the relatively low intake of distilled water which was also offered to the animals was not affected by any dose of ANP (32). Consequently, it appears that this peptide can definitely suppress dehydration and AII-induced drinking and is even more potent to suppress salt intake.

To evaluate the physiologic significance of various peptides in the control of water intake, we injected into the $3 \mathrm{~V}$ highly purified antibodies against peptides thought to be involved and injected control animals with normal rabbit serum in the same volume. Since the evidence was already quite strong that AII might be involved in the drinking which follows hemorrhage and depletion of extracellular fluid volume, we decided to evaluate its possible role in dehydration-induced drinking. Antiserum directed against AII was microinjected into the $3 \mathrm{~V}$ of rats which had been deprived of water overnight. We had previously found that frequently there is a delay following intraventricular injection of antiserum against peptides before they are effective. These delays may represent the time for the antiserum to be absorbed from the ventricle and to diffuse the site of action of the peptide. In this case, if water was offered immediately after injection of the antiserum, drinking was not altered. If water was offered $1 \mathrm{~h}$ after injection, drinking was largely blocked. At $3 \mathrm{~h}$ after injection of the antiserum, drinking was completely abolished. These results indicate that AII is required to induce the drinking which follows dehydration (33).

Previous attempts had been made to block dehydration-induced drinking with saralasin, an antagonist of AII; however, except for one experiment in the rat in which lateral ventricular infusion of saralasin commencing $30 \mathrm{~min}$ prior to giving the animals access to water partially suppressed drinking, these experiments with saralasin have been negative (34). These results contrast strikingly with the dramatic effectiveness of AII antiserum in blocking dehydration-induced drinking. We believe that the discrepancy is probably related to the short duration of action of saralasin, plus the failure to distribute it to the active sites following infusions into the lateral ventricle which would not distribute the antagonist uniformly bilaterally and therefore might not completely inactivate the AII receptors. We conclude that AII, either reaching the brain via the circulation and uptake via the circumventricular organs, or more likely released from neurons containing AII within the hypothalamus, which have been found in close association with ANP neurons, plays an essential role in dehydration-induced drinking. By contrast, AII appears to play no role in the normal prandial drinking that occurs concomitantly with feeding when the lights are turned off, because the antiserum injected $3 \mathrm{~h}$ before lights off had no effect on prandial drinking (33). A review on the interaction of ANP and AII in the central nervous system was published by Phillips (35).

\section{Hormonal effects of the brain ANP system}

In addition to altering water and salt intake and excretion, ANP has important actions on the release of anterior and posterior pituitary hormones (36). The peptide can inhibit the release of corticotrophin (ACTH) and prolactin, anterior pituitary hormones that are released during stress (37). To determine the physiologic significance of ANP in the control of basal and stress-induced release of anterior pituitary hormones, the same highly specific antiserum against the peptide (AB-ANP) which we had employed earlier (33) was microinjected into the $3 \mathrm{~V}$ of conscious, freely moving male rats to immunoneutralize hypothalamic ANP. In the initial experiment, the antiserum or control normal 
rabbit serum (NRS) was injected into the $3 \mathrm{~V}$ to determine the effect of the antiserum on basal release of pituitary hormones. The antiserum had no effect on the concentrations of plasma ACTH, prolactin, or thyroid-stimulating hormone (TSH) for $3 \mathrm{~h}$ after the injection; however, plasma growth hormone concentration, although unchanged for $2 \mathrm{~h}$, was markedly elevated at $3 \mathrm{~h}$. These results indicate that, although ANP appears to have no effect on the basal release of the other hormones, it has a physiologically significant inhibitory effect on growth hormone release. The delay of the effects is probably related to the time required for the antiserum to diffuse to the site of action, presumably at some distance from the ventricle.

Since this effect was demonstrable only after $3 \mathrm{~h}$, in the stress experiment the antiserum or NRS was microinjected into the $3 \mathrm{~V}$ $3 \mathrm{~h}$ prior to application of ether stress. The rapid elevation of plasma ACTH in NRSinjected rats was markedly augmented by AB-ANP. Ether also induced a rapid increase in plasma prolactin in the NRS-injected animals, as expected. Contrary to the ACTH response, the maximal increase in plasma prolactin after ether was attenuated in animals preinjected with AB-ANP.

In the NRS-injected animals, there was a significant decline in plasma growth hormone after the application of ether that was significantly accentuated by AB-ANP, but this was probably the result of the higher initial levels of plasma growth hormone in the AB-ANP group followed by its disappearance with a half-time similar to that of the NRS-injected group. The decline in plasma TSH after ether stress was unaltered in the animals injected with AB-ANP.

The results of these immunoneutralization studies suggest that endogenous ANP does not play a role in TSH release. On the other hand, the endogenous peptide appears to have a physiologically significant inhibitory role in suppressing ACTH release during stress, mediated at least partly by suppres- sion of VP release. Endogenous ANP has a pathophysiologic role in augmenting the prolactin release in stress either by inhibiting release of prolactin-inhibiting factors or, alternatively, by enhancing release of prolactin-releasing factors, such as OT. Endogenous ANP appears to inhibit resting, without altering stress-induced inhibition of growth hormone-releasing hormone release or by stimulating resting somatostatin release or by both actions $(36,37)$.

The results of our experiments appear to indicate that the increased release of ANP during stress dampens a number of responses to the stressful stimulus. For example, the inhibition by ANP of stress-induced VP release would increase renal water loss and the diminished ACTH release induced by the peptide would lead to reduction in aldosterone secretion thereby diminishing the sodium retention which characterizes stress. The ANP released in stress probably acts intrahypothalamically to suppress VP secretion and since VP augments ACTH secretion during stress, this diminution in VP release would lead to the decreased ACTH secretion. The increased prolactin release in stress induced by the increased endogenous ANP release probably would not augment sodium excretion since, at least under certain circumstances, prolactin appears to have a direct antinatriuretic effect on the kidney (38).

In contrast to these results with growth hormone, ACTH and prolactin, there was not only no effect of the antiserum on resting TSH values but also no alteration in the suppression of TSH release induced by ether stress. In other studies we have discovered the physiological significance of the suppressive action of ANP on basal luteinizing hormone but not follicle-stimulating hormone release (39).

In summary, these immunoneutralization experiments support the concept that in states of volume expansion the increased ANP released would act centrally to inhibit release of VP and ACTH. The inhibition of VP 
release would augment renal water loss and the reduction of aldosterone release consequent to decreased ACTH release would augment water and $\mathrm{Na}^{+}$loss, respectively, amplifying the natriuresis induced by ANP and hastening the return of the blood volume to normal.

\section{Brain ANPergic neuronal system and release of ANP}

The next question was the role of the brain ANPergic neuronal system in CNSinduced natriuresis brought on by intraventricular injection of hypertonic saline or activation of brain cholinergic and adrenergic circuits by carbachol or norepinephrine. We had earlier thought that these effects were brought about by the release of a hypothalamic natriuretic hormone. Alternatively, they could be brought about by neural activation of the release of ANP from the neurohypophysis or the atria.

Therefore, we evaluated the possible role of brain ANP in evoking the changes in renal sodium excretion that followed stimulations or lesions of the $\mathrm{AV} 3 \mathrm{~V}$, a region further implicated in control of sodium excretion by earlier experiments (6). Injection of carbachol into the AV3V produced the expected natriuresis on the basis of our earlier experiments, which was accompanied by a dramatic rise in the plasma ANP concentration and a rise in ANP content in the medial basal hypothalamus, the neurohypophysis and particularly the anterior hypophysis but without alterations in the content of ANP in the lungs or the right or left atrium. The dramatic increase in plasma ANP after carbachol stimulation of the AV3V was accompanied by marked elevations in the content of the peptide in basal hypothalamus and neuro- and adenohypophysis suggesting that the natriuresis resulting from this stimulation is brought about, at least in part, by the release of ANP from the brain (40).

Conversely, there was a dramatic decline in plasma ANP at both 24 and $120 \mathrm{~h}$ after AV3V lesions had been placed. This effect was accompanied by a slight decline in the content of the peptide in the lungs. There was no change in its content in the right atrium at $24 \mathrm{~h}$ after lesions, but there was a significant increase at $120 \mathrm{~h}$. These small changes contrasted sharply with the dramatic decline in the content of the peptide in the medial basal hypothalamus, median eminence, neurohypophysis, choroid plexus, anterior hypophysis and olfactory bulb. These declines persisted or became greater at 120 $\mathrm{h}$, except in the olfactory bulb in which the decline was no longer significant (40).

Therefore, lesions which destroyed the perikarya of ANPergic neurons caused a decline in ANP content in presumed projection areas of these neurons to the olfactory bulb, where they are probably involved in control of salt and water intake. ANP content of the choroid plexus also declined probably because of loss of input from the AV3V neurons. There is evidence that the ANP neuronal projection to the choroid plexus may be involved in cerebrospinal fluid formation. Destruction of the AV3V also caused loss of ANP from caudal axonal projections to the neurohypophysis, whereas only a delayed increase in left atrial ANP content occurred, probably related to decreased release of the peptide in the presence of continued synthesis which led to increased tissue content of the peptide (41).

The dramatic decline in plasma ANP after AV3V lesions was accompanied by a very dramatic decline in the content of ANP in regions containing the caudal axonal ANP neuronal connections to the median eminence and neural lobe of the pituitary gland, that was probably caused by release of these stores of the peptide which could not be replenished by axoplasmic flow of the peptide from the destroyed perikarya.

In view of the much larger quantities of the peptide stored in the atria, it is probable that changes in atrial release contribute to the alter- 
ations in plasma ANP observed after stimulation or ablation of the AV3V region; however, these results suggest that the dramatic changes in plasma ANP that followed the manipulations may be due to altered release of the peptide from brain structures as well as the atria and lungs $(40,41)$. These stimulation and lesion experiments support a crucial role of the CNS in controlling ANP release.

\section{Role of hypothalamic ANPergic neurons in volume expansion-induced release of ANP}

Expansion of the blood volume causes a release of ANP that is believed to be important in induction of the subsequent natriuresis and diuresis which, in turn, act to reduce the increase in blood volume. Since stimulation of the AV3V induced a rapid elevation of plasma ANP, whereas lesions of the AV3V were followed by a marked decline in plasma concentration of the peptide, we hypothesized that release of ANP from the brain ANP neuronal system might be important to the control of plasma ANP. As already described, the perikarya of the ANP-containing neurons are densely distributed in the AV3V and their axons project to the median eminence and neural lobe (4).

To test the hypothesis that these neurons are involved in volume expansion-induced ANP release, we destroyed the AV3V, the site of the perikarya, in male rats by electrolytic lesions. Other lesions were made in the median eminence and posterior pituitary, sites of termination of the axons of these neurons, and also hypophysectomy was performed in other animals (41).

In conscious freely moving animals, volume expansion and stimulation of postulated sodium receptors (12) in the hypothalamus were induced by injection of hypertonic $\mathrm{NaCl}$ solution ( 0.5 or $0.3 \mathrm{M} \mathrm{NaCl} ; 2 \mathrm{ml} / 100$ $\mathrm{g}$ body weight). Volume expansion alone was induced with the same volume of an isotonic solution $(\mathrm{NaCl}$ or glucose). In the sham-operated rats, volume expansion with hypertonic or isotonic solutions caused equivalent rapid increases in plasma ANP that peaked at $5 \mathrm{~min}$ and returned nearly to control values by $15 \mathrm{~min}$. Lesions caused a decrease in the initial levels of plasma ANP in comparison with values from the shamoperated rats, and each type of lesion induced a highly significant suppression of the response to volume expansion on testing 1-5 days after lesions were made.

Because a common denominator of the lesions was the elimination of the brain ANP neuronal system, these results suggest that the brain ANP plays an important role in the mediation of the release of ANP that occurs after volume expansion. Since the content of ANP in this system is 1000 -fold less than that in the atria, it is likely that release of brain ANP associated with this stimulus cannot account for the 4-fold increase in plasma ANP within $5 \mathrm{~min}$ of volume expansion. Therefore, a large increase in release from the atrium must occur. This could be mediated by efferent neural input to the atrium but cannot account for the ability of neural lobectomy to block volume expansion-induced ANP release since the lesions would not directly injure the CNS. Therefore, we hypothesized that volume expansion-induced release of other neurohypophyseal hormones, such as VP, OT or endothelin, may induce release of ANP from atrial myocytes (40).

In other experiments, we determined the essentiality of the brain ANP neuronal system to the blood volume expansion (BVE)induced ANP release induced by hypertonic saline by injecting antiserum directed against ANP into the AV3V prior to inducing volume expansion. The antiserum had no effect on resting levels of ANP; however, it partially blocked the increase in ANP and the natriuresis which followed BVE (42). Other experiments in sheep had given similar results (43). Therefore, it appears that the essentiality of the nervous system in these responses of ANP to volume expansion is 
conferred by the ANP neuronal system.

Previously, we have shown that cholinergic and adrenergic synapses within the hypothalamus mediated the natriuresis induced by $3 \mathrm{~V}$ injection of hypertonic saline (12). Therefore, we evaluated their role in the ANP release evoked by volume expansion. The receptor-blocking agents were injected into the $3 \mathrm{~V} 30 \mathrm{~min}$ prior to BVE as previously described. These blockers had no effect on resting levels of the hormone just prior to BVE; however, a highly significant blockade of the response was induced by the prior injection of the muscarinic cholinergic receptor blockers, atropine sulfate $(5 \mu \mathrm{mol}$ in $2 \mathrm{ml} 0.9 \% \mathrm{NaCl}$ ) or methyl atropine at a similar dose. Microinjection of the alpha receptor blocker, phentolamine $(5 \mu \mathrm{mol}$ in 2 $\mathrm{ml}$ saline) also markedly suppressed the ANP response (44).

To determine whether this was a central or possibly a systemic effect of the blockers, methyl atropine $(0.01 \mathrm{nmol} / 100 \mathrm{~g}$ body weight), which does not cross the bloodbrain barrier, was injected ip $30 \mathrm{~min}$ before volume expansion. It also had no effect on basal levels of plasma ANP, but in striking contrast to the blockade of the response to volume expansion induced by intraventricular injection of methyl atropine, the response to volume expansion was markedly enhanced by ip injection of methyl atropine. The results therefore indicate that hypothalamic muscarinic and alpha adrenergic synapses are essential to release of ANP in response to volume expansion (44).

Thus, the results to this point indicated the crucial participation of the CNS and the brain ANP neurons in the response of ANP and natriuresis to volume expansion. We considered the possibility that the baroreceptors, when stretched by volume expansion, would activate the brain ANP neurons which would then produce the release of ANP and the ensuing natriuresis. Therefore, we determined the role of the baroreceptors in affecting the increase in plasma ANP from volume expansion induced by $i v$ injection of hypertonic saline solution $(0.3 \mathrm{M} \mathrm{NaCl}, 2 \mathrm{ml} /$ $100 \mathrm{~g}$ body weight, over $1 \mathrm{~min}$ ) into conscious, freely moving male rats (45). In shamoperated rats, BVE induced a rapid increase in plasma ANP as before. The concentration peaked at $5 \mathrm{~min}$ and remained elevated at 15 min after saline injection. One week after deafferentation of the carotid-aortic baroreceptors, basal plasma ANP concentrations were highly significantly decreased in comparison with values of sham-operated rats; plasma ANP levels 5 min after BVE in the deafferented rats were greatly reduced. Unilateral right vagotomy reduced resting levels of plasma ANP but not the response to BVE; resting concentrations of plasma ANP and responses to expansion were normal in bilaterally vagotomized rats. In rats that had undergone renal deafferentation, resting levels of ANP were normal but the response to BVE was significantly suppressed.

The evidence indicates that afferent impulses via the right vagus nerve may be important under basal conditions, but they are not required for the ANP release induced by BVE. In contrast, baroreceptor impulses from the carotid-aortic sinus regions and the kidney are important pathways involved in neuroendocrine control of ANP release. Others have also found that the carotid-aortic baroreceptors are important in mediating the response (46). The evidence from these experiments and our previous stimulation and lesion studies indicates that the ANP release in response to volume expansion is mediated by afferent baroreceptor input to the AV3V region, which mediates the increased ANP release via activation of the hypothalamic ANP neuronal system $(40,41)$.

\section{Role of the locus coeruleus and raphe nuclei in transmission of afferent input to the AV3V region}

Since baroreceptor afferents terminate in the nucleus tractus solitarius (NTS), we hy- 
pothesized that baroreceptor impulses to the NTS might be relayed to the locus coeruleus which would then transmit the information by axons of the noradrenergic neurons located there to the $\mathrm{AV} 3 \mathrm{~V}$ region. Indeed, lesions of the locus coeruleus lowered resting ANP levels and blocked the response of ANP to volume expansion (47). We speculate that the axons of these noradrenergic neurons projecting to the $\mathrm{AV} 3 \mathrm{~V}$ region activate cholinergic interneurons there, which in turn stimulate the hypothalamic ANPergic neurons. These neurons would activate efferent neurohumoral or neural pathways, which induce the release of ANP from the brain and in much greater quantities from the atria (44).

An afferent pathway to the $\mathrm{AV} 3 \mathrm{~V}$ region via serotonergic (5-HTergic) neurons with cell bodies in the raphe nuclei has been demonstrated (48). Therefore, we hypothesized that 5-HT may play a role in the control of ANP neurons in the region of the AV3V. Indeed, earlier studies have shown that injection of 5-HT agonists into the third or lateral ventricle could increase plasma ANP, and that the responses were prevented by $5-\mathrm{HT}_{2}$ receptor blockers (49). To determine the effect of loss of 5-HT input into the AV3V region, bilateral lesions were placed in the dorsal raphe nuclei (DRN), a major source of 5-HT neurons that project to the AV3V region, and in other animals, depletion of 5-HT from 5-HTergic neurons was accomplished by systemic administration of parachlorophenylalanine (PCPA), an amino acid that competes with tryptophan, the substrate of tryptophan hydroxylase, the ratelimiting enzyme in the synthesis of indoleamines (50).

Rather surprisingly at first glance, the DRN lesions produced a diabetes insipiduslike state in which there was a highly significant increase in water intake and urine volume beginning on the 1st day following lesions, reaching a peak of water intake at 3 days, followed by gradual decline in water intake and urine volume to control levels one week after the lesions had been placed. During the diuresis, the osmolality of the urine was dramatically reduced as was the sodium excretion. When the animals were waterloaded and sodium excretion was measured on day 2 after lesions, the excretion was of sodium was drastically lowered. However, this had recovered by 4 and 14 days after the lesions.

We believe that these changes were due to a drastic suppression of ANP release since the basal levels of ANP were reduced in a highly significant manner and concluded that the serotonergic system has a tonic stimulatory drive on the release of ANP. When this ANP drive is removed by the lesions, there may be a removal of tonic inhibition by ANP of AII-secreting neurons within the AV3V region resulting in increased AII release which then brings about an increase in water intake. At the same time, the reduction in ANP output causes a reduction in renal sodium excretion. Consequently, water intake is increased leading to reduction in VP release and a hypotonic urine with drastically reduced sodium concentration. The animals recovered, probably because the DRN is not the only source of serotonergic input, which is also delivered through the median raphe nuclei. Depletion of 5-HT from these serotonergic cells also produced a similar picture (50).

When the rats with PCPA lesions were water-loaded 5 days after lesions, they showed a similar reduction in natriuresis as that of the rats with DRN lesions. The results differed from those in rats with DRN lesions only in that there was also a significant reduction in kaliuresis in the PCPA-injected rats. These effects were probably also due to reduced serotonergic input to the AV3V region and thereby reduced stimulation of the ANP neurons with resultant reduction in plasma ANP. As in the case of the DRN lesions, not only were the initial levels of plasma ANP significantly lowered, but also 
the response of plasma ANP to BVE was significantly reduced, although the reduction was not complete as was the case for the DRN lesion group of animals.

Therefore, we concluded that there was a tonic stimulatory input from the 5-HT neurons to the hypothalamic ANP neurons, which when removed, resulted in disinhibition of AII release causing increased water intake and decreased ANP release into the circulation resulting in sodium retention. The raphe nuclei may be stimulated by afferent input from the baroreceptors via the NTS and this then may be in part responsible for the stimulation of ANP release which occurs following volume expansion. Alternatively, a tonic stimulatory drive via these neurons may be all that is required to have the volume expansion-induced release of ANP, and the major stimulation may be via the locus coeruleus with increased noradrenergic drive to the AV3V region. Further work will be necessary to distinguish between these two possibilities.

We have illustrated (Figure 1) the putative pathway of activation of ANP release and natriuresis via volume expansion. This pathway involves distention of baroreceptors in the right atrium, carotid and aortic sinuses and in the kidney which alters their afferent input to the brain stem in the nucleus tractus solitarius. Impulses from there activate the locus coeruleus since lesions of the locus coeruleus, a major source of noradrenergic axons to the hypothalamus, lower resting ANP. The axons of these noradrenergic neurons projecting to the AV3V region activate cholinergic interneurons there, which in turn stimulate the hypothalamic ANPergic neurons. These neurons would activate efferent neurohumoral or neural pathways which induce the release of ANP from the brain and the atria.

\section{Efferent pathways by which volume expansion stimulates ANP release}

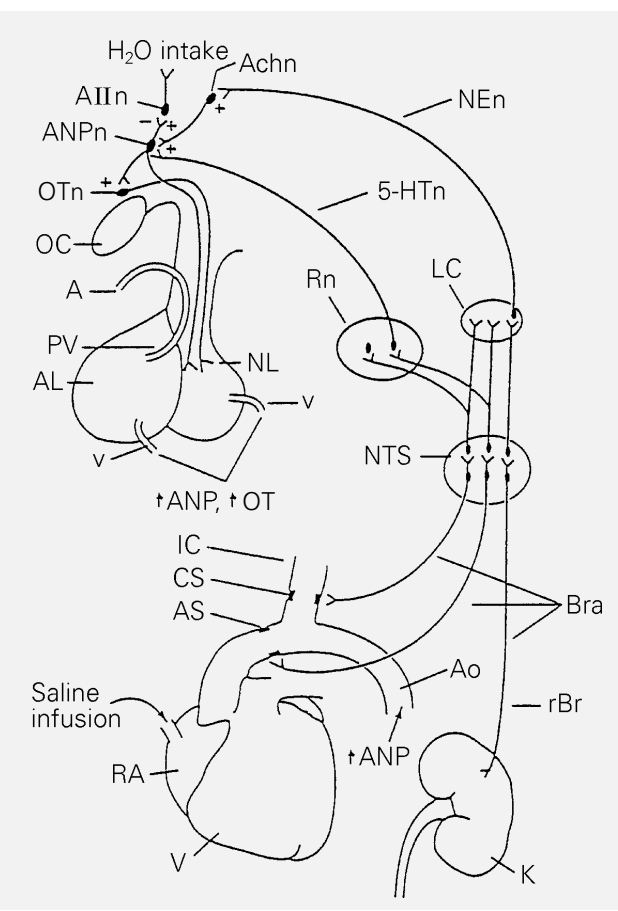

Some of the ANP neurons terminate in the median eminence and neural lobe of the hypophysis. It is probable that their activation leads to release of the peptide into the vasculature draining the median eminence or the neural lobe. Since the quantity of ANP is more than 1000 -fold less in these structures than in the atria (40), we believe that ANP released from the brain plays a minor role in the response. Rather, we would suggest that these ANPergic neurons activate descending pathways which then activate efferent pathways to the heart with the consequent release of ANP from cardiac myocytes. Combined release from both sources then accounts for the increase in plasma ANP concentrations which mediate the ensuing natriuresis. We do not believe that the efferent pathway to the heart is principally neural. It cannot be cholinergic since bilateral section of the vagi does not block the response to volume expansion. It is unlikely that it is a sympathetic efferent pathway since volume expansion by elevating blood pressure should, if anything, diminish sympathetic outflow. There is a possibility that there could be an unknown efferent pathway
Figure 1 - Schematic diagram of the ANP neuronal control of ANP release. For explanation see the text. AIIn, Angiotensin II neuron; Achn, acetylcholinergic neuron; NEn, norepinephrinergic neuron; ANPn, ANPergic neuron; OTn, oxytocinergic neuron; 5-HTn, 5-HTergic neuron; OC, optic chiasm; A, artery; PV, portal vessel; $A L$, anterior lobe of the pituitary gland; $N L$, neural lobe of the pituitary gland; $v$, vein; $R n$, raphe nuclei; LC, locus coeruleus; NTS, nucleus tractus solitarius; IC, internal carotid artery; CS, carotid sinus; AS, aortic sinus; Ao, aorta; RA, right atrium; $\mathrm{V}$, ventricles; Bra, baroreceptor afferents; $\mathrm{rBr}$, renal baroreceptor afferents; K, kidney; OT, oxytocin. (From Ref. 50 , with permission). 
reaching the atria, perhaps peptidergic in nature, or even nitricoxidergic.

Instead, we believe that release of brain peptides induced by ANP neurons is probably the major pathway. These peptides circulate to the atria and there act directly on atrial myocytes to stimulate the release of ANP. Because there was a large amount of endothelin discovered in the neural lobe, we evaluated the possibility that this could be the activator of the release of ANP by the atrial myocytes. However, our data indicate that this is unlikely (51). $\alpha-\mathrm{MSH}$ is also natriuretic and we evaluated its effect on ANP release, but so far the results have not been impressive. The major peptides of the neurohypophysis are vasopressin (VP) and oxytocin (OT). Both are natriuretic in the rat, but OT is by far the most potent of these natriuretic peptides and in our earlier experi-

Figure 2 - Schematic diagram of the mechanism of natriuresis following blood volume expansion (BVE) by injection of isotonic saline into the right atrium. See Figure 1 legend for abbreviations. S, Pituitary stalk; SVC, superior vena cava; AM, atrial myocytes. (From Ref. 52 , with permission).

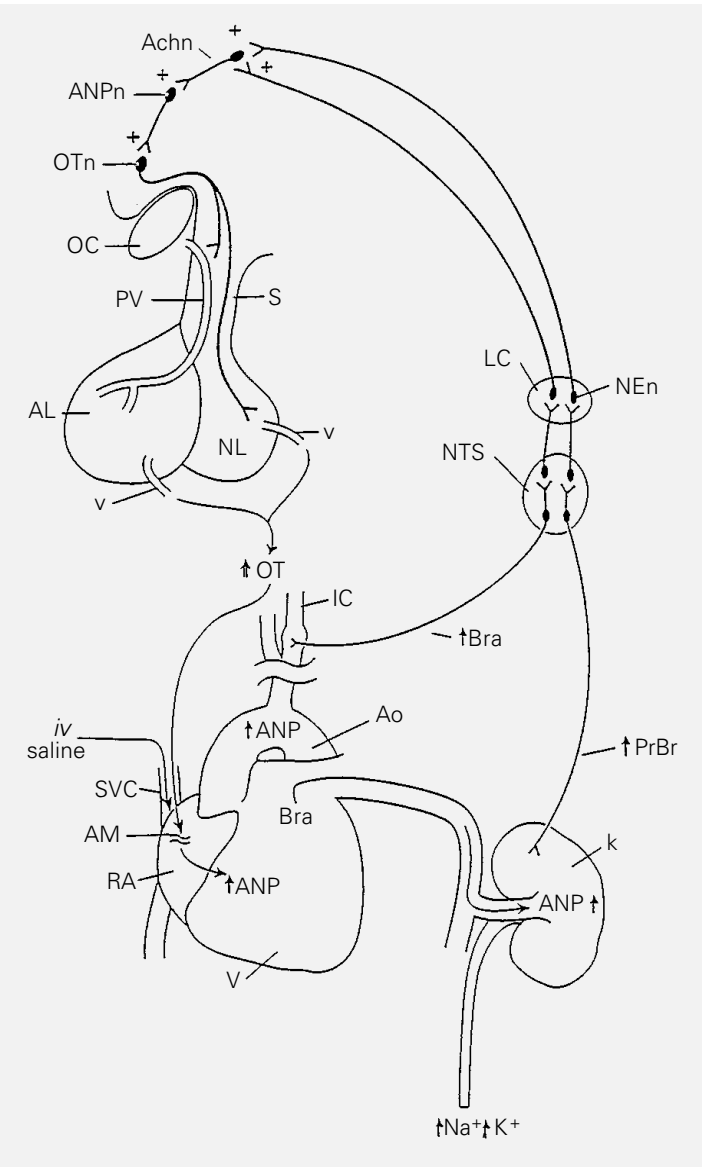

ments, we considered the possibility that OT was indeed the natriuretic peptide (22).

Therefore, we reevaluated the role of OT in natriuresis and ANP release induced by volume expansion (52). OT (1-10 nmol) injected ip into water-loaded conscious rats caused significant dose-dependent increases in urinary osmolality, natriuresis and kaliuresis, results exactly similar to those obtained by volume expansion in the conscious water-loaded rat under the same conditions used in all our prior experiments. Plasma ANP concentrations increased nearly 4-fold 20 min after this dose of OT, but there was no change in plasma ANP values in control animals. OT ( 1 or $10 \mathrm{nmol})$ injected $i v$ induced a dose-related increase in plasma ANP peaking at $5 \mathrm{~min}$. Therefore, we have demonstrated that OT can indeed induce natriuresis and kaliuresis and furthermore that it induces a concomitant release of ANP at the concentrations and with the same time course as that previously found with BVE. Furthermore, OT $(1$ or $0.1 \mu \mathrm{M})$ evoked a release of ANP from incubated rat atria which was blocked by an OT antagonist (Ferring, Malmö, Sweden). The antagonist ( $1 \mu \mathrm{M}$ and $1 \mathrm{nM}$ ) reduced basal ANP release. The data suggest that OT may be a physiologically significant releaser of ANP (53).

To determine if indeed BVE induces OT as well as ANP release, intra-atrial injections of isotonic saline were given $(2 \mathrm{ml} / 100 \mathrm{~g}$ body weight), which induced a rapid (5 min post-injection) increase in plasma OT and ANP concentrations and a concomitant decrease in plasma arginine VP concentration (52). When hypertonic volume expansion was produced by injection of $0.3 \mathrm{M} \mathrm{NaCl}$, which should also stimulate putative osmoor sodium receptors and might be expected to cause a secretion of VP, there was a greater increase in plasma ANP and also OT, but not significantly different from the increases in the isotonic volume-expanded animals. However, in contrast to isotonic volume expansion, there was a transient (5 
min) increase in plasma arginine VP.

We have already shown that suckling, which causes the release of OT, increases plasma ANP in rats, and that an OT antagonist injected $15 \mathrm{~min}$ prior to suckling completely blocked the increase in ANP caused by suckling (Haanwinckel MA and AntunesRodrigues J, unpublished results). Experiments are currently underway to determine if OT antagonists can similarly block the ANP release caused by volume expansion.

Consequently, we have proposed the hypothesis that baroreceptor activation of the CNS by BVE stimulates the release of OT from the neurohypophysis (Figure 2). This OT circulates to the right atrium to induce release of ANP. ANP circulates to the kidney and induces natriuresis and diuresis which restore body fluid volume to normal levels. It is not clear whether or not OT has a separate, independent natriuretic action which is additive or synergistic with the action of ANP. Studies with antisera directed against the peptides and receptor blockers will be necessary to reveal this.

It has been noteworthy throughout all these studies that smaller changes in potassium excretion parallel those in sodium excretion, although they are not so pronounced. We found this also to be the case with injection of OT. Similarly, ANP produces a greater natriuresis but a significant kaliuresis (54). Consequently, we concluded that OT and
ANP can account for the kaliuresis which also follows volume expansion, and for the decrease in potassium excretion which also occurs along with the decrease in sodium excretion when there is a reduction in ANP release. This view may need modification with the recent discovery of a kaliuretic peptide which produces kaliuresis with little or no natriuresis and is the 20-amino acid peptide aminoterminal extension of ANP (55).

Furthermore, it has now been shown in man that water-immersion to the neck, as would be expected from results obtained even in the middle ages, produces diuresis, natriuresis and kaliuresis. Vesely et al. (55) have shown that in this situation, there is an elevation of plasma concentrations of both kaliuretic peptide and ANP. However, the time course of the ensuing kaliuresis is more easily explained on the basis of increased concentrations of kaliuretic peptide than ANP. Therefore, it is possible that stimuli which either increase or decrease plasma ANP also produce a concomitant stimulation or inhibition of the release of kaliuretic peptide. Further experiments are needed to determine whether both peptides are involved in the changes or only ANP.

\section{Acknowledgments}

We would like to thank Judy Scott and Jason Holland for excellent secretarial assistance.

\section{References}

1. Welt LG, Seldin DW, Nelson WP, German WJ \& Peters JP (1952). Role of the central nervous system in metabolism of electrolytes and water. Archives of Internal Medicine, 90: 355.

2. Andersson B \& McCann SM (1955). A further study of polydipsia evoked by hypothalamic stimulation in the goat. Acta Physiologica Scandinavica, 33: 333-346.

3. Andersson B \& McCann SM (1955). Drinking, antidiuresis and milk ejection from electrical stimulation within the hypothalamus of the goat. Acta Physiologica Scandinavica, 35: 191-201.
4. Palkovits M, Eskay RL \& Antoni FA (1987). Atrial natriuretic peptide in the median eminence is of paraventricular nucleus origin. Neuroendocrinology, 46: 542-544.

5. Andersson B \& McCann SM (1956). The effects of hypothalamic lesions on the water intake of the dog. Acta Physiologica Scandinavica, 35: 312-320.

6. Brody MJ \& Johnson AK (1985). Role of the anteroventral third ventricle region in fluid and electrolyte balance, arterial pressure regulation, and hypertension. In: Martini L \& Ganong WF (Editors), Frontiers of Neuroendocrinology. Raven Press, New York, 249-292.
7. Andersson B, Jobin M \& Olsson K (1966) Stimulation of urinary salt excretion following injections of hypertonic $\mathrm{NaCl}$ solution into the third brain ventricle. Acta Physiologica Scandinavica, 67: 127-128.

8. Dorn J \& Porter JC (1970). Diencephalic involvement in sodium excretion in the rat. Endocrinology, 78: 1112-1117.

9. Antunes-Rodrigues $J$ \& McCann SM (1970). Chemical stimulation of water, sodium chloride and food intake by injections of cholinergic and adrenergic drugs into the third brain ventricle. Proceedings of the Society for Experimental Biology and Medicine, 133: 1464-1470. 
10. Grossman SP (1964). Some neurochemical aspects of the central regulation of thirst. In: Wayner MJ (Editor), Thirst. Pergamon Press Inc., New York, 487-514.

11. Dorn J, Antunes-Rodrigues J \& McCann SM (1970). Natriuresis in the rat following intraventricular carbachol. American Journal of Physiology, 219: 1292-1298.

12. Andersson B (1977). Regulation of body fluids. Annual Review of Physiology, 39: 185-200

13. Morris M, McCann SM \& Orias R (1977). Role of transmitters in mediating hypothalamic control of electrolyte secretion. Canadian Journal of Physiology and Pharmacology, 55: 1143-1154.

14. Petrovic SL, McDonald JK, Bedran de Castro JC, Snyder GD \& McCann SM (1985). Regulation of anterior pituitary and brain beta-adrenergic receptors by ovarian steroids. Life Sciences, 37: 15631570.

15. Covian MR, Antunes-Rodrigues J, Gentil CG, Saad WA, Camargo LAA \& Silva-Neto CR (1975). Central control of salt balance in neural integration of physiological mechanisms and behavior. In: Mogenson CJ \& Calaresu FR (Editors), Neural Integration of Physiological Mechanisms and Behavior. University of Toronto Press, Toronto, 267-282.

16. Covian MR \& Antunes-Rodrigues J (1963). Specific alterations in sodium chloride intake after hypothalamic lesion in the rat. American Journal of Physiology, 205: $922-$ 926.

17. de Wardener HE \& Clarkson EL (1985). Natriuretic hormone. In: Seldin DW \& Giebisch G (Editors), The Kidney: Physiology and Pathophysiology. Raven Press, New York, 1013-1031.

18. Davis JO \& Freeman RH (1976). Mechanisms regulating renin release. Physiological Reviews, 56: 1-56.

19. Cort JH, Lichardus B, Pliska V, Barth T, Uhrin $V$ \& Rudinger J (1969). In: Margoulies J (Editor), Protein and Polypeptide Hormones. Excerpta Medica, Amsterdam.

20. Orias R \& McCann SM (1970). Natriuretic effect of $\alpha-\mathrm{MSH}$ in the water-loaded rat. Proceedings of the Society for Experimental Biology and Medicine, 133: 469-474.

21. Orias R \& McCann SM (1972). Natriuretic effect of alpha-melanocyte stimulating hormone in hypophysectomized or adrenalectomized rats. Proceedings of the Society for Experimental Biology and Medicine, 139: 872-876.
22. Orias R \& McCann SM (1972). Natriuresis induced by alpha and beta melanocyte stimulating hormone (MSH) in rats. Endocrinology, 90: 700-706.

23. Morris M, McCann SM \& Orias R (1976). Evidence for hormonal participation in the natriuretic and kaliuretic responses to intraventricular hypertonic saline and norepinephrine. Proceedings of the Society for Experimental Biology and Medicine, 152: 95-98

24. Orias R \& McCann SM (1971). Natriuresis following intraventricular hypertonic saline in rats with hereditary diabetes insipidus. Abstract of the 10th Congreso Latino Americano de Ciencias Fisiológicas, Caracas, Venezuela.

25. DeBold AJ, Bovenstein HB, Veress AT \& Sonnenberg $H$ (1981). A rapid and potent natriuretic response to intravenous injection of atrial myocardial extract in rats. Life Sciences, 28: 89-94.

26. Gauer OH \& Henry JP (1963). Circulatory phases of fluid volume control. Physiological Reviews, 43: 423-481.

27. Synhorst DP \& Gutkowska J (1988). Atrial distension of isolated rabbit hearts and release of ANP. American Journal of Physiology, 255: R232-R236.

28. Samson WK (1985). Dehydration-induced alterations in rat brain vasopressin and atrial natriuretic factor immunoreactivity. Endocrinology, 117: 1279-1281.

29. Blaine EH \& Rosenblatt M (1987). ANF: A hormone from the heart. In: McCann SM (Editor), Endocrinology: People and Ideas. American Physiological Society, Bethesda, 397-420

30. Skofitsh G, Jacobowitz DM, Eskay RL \& Zamir N (1985). Distribution of ANF-like immunoreactive neurons in the rat brain. Neuroscience, 16: 917-948.

31. Antunes-Rodrigues J, McCann SM, Rogers LC \& Samson WK (1985). Atrial natriuretic factor inhibits water intake in conscious rats. Proceedings of the National Academy of Sciences, USA, 82: 8720-8724.

32. Antunes-Rodrigues J, McCann SM \& Samson WK (1986). Central administration of atrial natriuretic factor inhibits salt intake in the rat. Endocrinology, 118: 1726-1729

33. Franci CR, Kozlowski GP \& McCann SM (1989). Water intake in rats submitted to hypothalamic immunoneutralization of angiotensin II, atrial natriuretic peptide, vasopressin or oxytocin. Proceedings of the National Academy of Sciences, USA, 86: 2952-2956.
34. Malvin RLM, Mouwd D \& Vander AJ (1977). Angiotensin: physiological role in water deprivation-induced thirst of rat. Science, 197: 171.

35. Phillips MI (1987). Functions of angiotensin in the central nervous system. Annual Review of Physiology, 49: 413-435.

36. Samson WK \& Bianchi R (1988). Further evidence for a hypothalamic site of action of atrial natriuretic factor: inhibition of prolactin secretion in the conscious rat. $\mathrm{Ca}$ nadian Journal of Physiology and Pharmacology, 66: 301-305

37. Franci CR, Anselmo-Franci JA \& McCann SM (1992). The role of endogenous atrial natriuretic peptide in resting and stressinduced release of corticotrophin, prolactin, growth hormone, and thyroid-stimulating hormone. Proceedings of the $\mathrm{Na}$ tional Academy of Sciences, USA, 89: 11391-11395

38. Stier CT, Cowden EA, Friesen HG \& Allison MEM (1994). Prolactin and the rat kidney: a clearance and micropuncture study. Endocrinology, 115: 362-367.

39. Franci CR, Anselmo-Franci JA \& McCann SM (1990). Opposite effects of central immunoneutralization of angiotensin II or atrial natriuretic peptide on luteinizing hormone release in ovariectomized rats. Neuroendocrinology, 51: 684-688.

40. Baldissera S, Menani JV, Sotero dos Santos LF, Favaretto ALV, Gutkowska J, Turrin MQA, McCann SM \& AntunesRodrigues J (1989). Role of the hypothalamus in the control of atrial natriuretic peptide release. Proceedings of the National Academy of Sciences, USA, 86: 9621 9625

41. Antunes-Rodrigues J, Ramalho MJ, Reis LC, Menani JV, Turrin MQA, Gutkowska J \& McCann SM (1991). Lesions of the hypothalamus and pituitary inhibit volume expansion-induced release of atrial natriuretic peptide. Proceedings of the $\mathrm{Na}$ tional Academy of Sciences, USA, 88: 2956-2960.

42. Antunes-Rodrigues J, Picanço-Diniz DWL, Favaretto ALV, Gutkowska J \& McCann SM (1993). Brain atrial natriuretic peptide neurons play an essential role in volume expansion-induced release of atrial natriuretic peptide and natriuresis. Neuroendocrinology, 58: 696-700.

43. Charles J, Tang F, Cameron VA, Richards AM \& Espiner EA (1991). Intracerebral ANF antiserum inhibits volume-induced ANF in sheep. Endocrinology, 129: 22252230 
44. Antunes-Rodrigues J, Marubayashi U, Favaretto ALV, Gutkowska J \& McCann SM (1993). Essential role of hypothalamic muscarinic and $\alpha$-adrenergic receptors in atrial natriuretic peptide release induced by blood volume expansion. Proceedings of the National Academy of Sciences, USA, 90: 10240-10244.

45. Antunes-Rodrigues J, Machado BH, Andrade HA, Mauad H, Ramalho MJ, Reis LC, Silva-Netto CR, Favaretto ALV, Gutkowska J \& McCann SM (1992). Carotid-aortic and renal baroreceptors mediate the atrial natriuretic peptide release induced by blood volume expansion. Proceedings of the National Academy of Sciences, USA, 89: 6829-6831.

46. Morris M \& Alexander N (1988). Carotid aortic baroreceptor. Endocrinology, 122: 373-375.

47. Anselmo-Franci JA, Peres-Polon VL \& Antunes-Rodrigues J (1992). Papel pressor da região anterior do "locus coeruleus" pela inibição da secreção de ANP durante a expansão de volume em ratos não anestesiados. IX Reunião Anual da Federação das Sociedades de Biologia Experimental, Caxambu, MG, Brasil, Abstract 2.10, p. 93.
48. Stein JM, Lind RW \& Johnson AK (1987). Central serotonergic influences on renal electrolyte and water excretion. Neuropharmacology, 26: 1685-1692.

49. Reis LC, Ramalho MJ \& AntunesRodrigues J (1991). Effect of central administration of serotoninergic agonists on electrolyte excretion control. Brazilian Journal of Medical and Biological Research, 24: 847-854.

50. Reis LC, Ramalho MJ, Favaretto ALV, Gutkowska J, McCann SM \& AntunesRodrigues J (1994). Participation of the ascending serotonergic system in the stimulation of atrial natriuretic peptide release. Proceedings of the National Academy of Sciences, USA, 91: 12022-12026.

51. Antunes-Rodrigues J, Ramalho MJ, Reis LC, Picanço-Diniz DWL, Favaretto ALV, Gutkowska J \& McCann SM (1993). Possible role of endothelin acting within the hypothalamus to induce the release of atrial natriuretic peptide and natriuresis. Neuroendocrinology, 58: 701-708.
52. Haanwinckel MA, Elias LK, Favaretto ALV, Gutkowska J, McCann SM \& AntunesRodrigues J (1995). Oxytocin mediates atrial natriuretic peptide release and natriuresis after volume expansion in the rat. Proceedings of the National Academy of Sciences, USA, 92: 7902-7906.

53. Favaretto ALV, Albuquerque-Araújo WIC Ballejo G \& Antunes-Rodrigues J (1996). Oxitocina (OT) estimula a liberação do peptídeo natriurético atrial (ANP) do átrio cardíaco direito in vitro. XI Reunião Anual da Federação de Sociedades de Biologia Experimental, Caxambu, MG, Brasil, Abstract 08.013, p. 166

54. Martin DR, Perahouse JB, Trigg DJ, Vesely DL \& Buerkert JE (1990). Three peptides from ANF prohormone $\mathrm{HG}_{2}$-terminus are natriuretic and/or kaliuretic. American Journal of Physiology, 258: F1401-F1408.

55. Vesely DF, Norsk P, Gower WR, Chiou S \& Epstein M (1995). Release of kaliuretic peptide during immersion-induced central hypervolemia in healthy humans. Proceedings of the Society for Experimental Biology and Medicine, 209: 20-26. 